\title{
Discussion on Quaternary sea-level change on the continental shelf of Hong Kong
}

\section{Ian Fairchild}

Journal of the Geological Society; Nov 1998; 155, Academic Research Library pg. 1053

\section{Discussion on Quaternary sea-level change on the continental shelf of Hong Kong}

\author{
Journal, vol. 154, 1997, pp. 1031-1038
}

W. W.-S. Yim, A. M. S. F. Choy, A. M. Davis \& G. Huang write: Fyfe et al. (1997) have provided a sequence stratigraphical interpretation of the Quaternary inner shelf sediments of Hong Kong based on the study of high-resolution seismicreflection profiles and continuously sampled boreholes. These authors claimed that the sequence is no older than Oxygenisotope stage 6. Furthermore by using terms including Eemian and Weichselian. they implied that direct correlation with the European sequence was possible. It may be useful. however. to examine the broader implications of their stratigraphy as a test of its validity.

Very few "stable" silieiclastic-dominated shelves in the world possess the amount of offshore enginecring site investigation data like Hong Kong (see for example Pinches 1996). Becaluse of this. Hong Kong is one of the best areas in the world for studying the Quaternary sequence on the inner shell. Fyte a al. (1997) considered the Chek Lap Kok Formation which is up to over $80 \mathrm{~m}$ in thickness to be Middle to Upper Pleistocene (stage 6): the Sham Wat Formation which is up to over $50 \mathrm{~m}$ in thickness to be Eemian (stalge 5e); the Waglan Formation which is up to $13 \mathrm{~m}$ in thickness to be Weichselian (stage 5e) and the Hang Hau formation which is up to $60 \mathrm{~m}$ in thickness to be Holocene/last glacial (stages 1 and 2). The above conclusions hate important consequences on shelf sedimentation and continental erosional rates. There are at least five problems with the interpretation of Fyfe et al. (1997). First. the age relationships between the pre-Holocene Formations. PreHolocene radiocarbon dates in Hong Kong are known to show a voung a a bias (Yinn el al. 1990). At least some of the finite radiocarbon dates of marine shells were suggested by Y'im at al. (1990) to be stage 5e. Price at al. (1996) have recently obtained stage 8 thermolumineseence dates from alluvial sands within the in called Chek Lap Kok Formation at the new Hong Kong Airport site. Second, the $60 \mathrm{~m}$ thick Hang Hau Formation identified in southeastern Hong Kong waters is inconsistent with the sedimentary environment. Why should this Formation be at a maximum thickness at a location in relatively deep waters far away from the known sources of sediment supply? The main terrigenous source of sediment supply is from the Pearl River in western Hong Kong waters. A maximum thickness of $17.8 \mathrm{~m}$ for Holocene sediments in Hong Kong was found at Tai O in southwestern Hong Kong (Yim 1994: Yim at al. 1996b) where the high sedimentary rate is favoured by the low-energy environment and high allus ial input. Third, there is an alternative model to Fyfe of al. (1997) which explains satisfactorily the offshore sequence including the engineering properties of the offshore sediments (Yim 1994). Examples include the tip resistance of cone penetrometer test profiles (Endicott 1992) and the properties of soil microfabrics including pore-water chemistry (Tovey 1992). Fourth. a seatlloor sediment survey of the South China Sea shell by Viino \& Emery (1961) revealed widespread relict sediment on both the middle and outer shelf. The widespread oceurrence of sand and gravel and occasionally bedrock on the sea floor of the outer shell is indicative of a decreatse in thickness of Holocene deposits offshore. About 70': of the area of the continental shelves of the world was estimated by Emery (1968) to be covered by relict sediments of presumably pre-Holocene age. Fifth. the shorteoning of using a constant seismic velocity of $1.6 \mathrm{~km} \mathrm{~s}^{-1}$ for interpreting seismic traces. Whether the first identifiable reflector below the present seat floor represented the true base of the Holocene is open to question.

The representative seismic profiles of the Quaternary offshore sediments of Hong Kong shown in fig. 3 are misleading For the identification of the base of the Hang Hau Formation. Out of the seven profiles shown. Only the shallowest R? reflector in profile $\mathrm{C}$ is considered by us to be successful in showing the base of the Holocene deposits. This is explained by the development of desiccated crusts formed by the subaerial exposure of interglacial deposits during glacial period(s) (Yim \& Tovey 1995). The remaining profiles were from sites with low rates of Holocene sedimentation. Protiles $A$ and $G$ are sites influenced by tidal current scouring. while profiles $B$. $D$. E and $F$ were from the deeper waters locited furthest away from known terrigenous sources. On the other hand. the offshore geological model of Yim (1994) with a sequence dating back to stage 12 with disconformities separating the marine (M) and terrestrial (T) units of stages 1 (MI). 2 (T1). 5 (M2). $6(\mathrm{~T} 2) .7(\mathrm{M} 3) .8(\mathrm{~T} 4) .9(\mathrm{M} 4) .10(\mathrm{~T} 4) .11(\mathrm{M} 5)$ and 12 (T5) respectively provided a satisfactory explanation including the enginecring properties of the deposits.

The reference to the uranium-series method date bivalve al $142000+20000$ vears BP (Yim of al. 1990) as the ade of the Chek Lap Kok Formation by Fyfe et al. (1997) is misleading as was previously pointed out in Yim \& Fyfe (1992). This shell has not remained under a closed system and the age of the shell can only be used as a rough guide. A closed system bivalse dated at $130500 \pm 5300$ years bP (Yim or al 1990) als was indicated by an initial ${ }^{2+4} \mathrm{C} / \mathrm{F}^{2 \times} \mathrm{U}$ activity ratio within 1 wo standard deviations of the sea water value of $1.15 \pm 0.01$ suggested by Thurber ot al (1965) wats ignored by Fyfe at al. (1997). Other evidence including the palynological distribution and the elevation of the deposits (Yim it at. 199()) also supported a stage 5 age for the M2 unit while the presence of foraminifera and other marine shells within the Chek Lap Kok Formation type locality was demonstrated in borehole MH1 studied by Yim \& Li (1983).

Recent work on the measurement of magnetic susceptibility in cores obtained from vibrocoring ( $\mathrm{Yim}$ ' $/$ al. 1996a) have shown that the Holocene/Pleistocene boundary can be identified successfully even when the underlying desiccated crust is poorly developed such as though the release of gas hodrates from the underlying sediments (Wong 1996). Below the desiccated crusts, there is a tendency for the sediments to become soft with a decrease in density. Similarly continuous moisture content measurements in a borehole (Choy 1997) provided a convenient means of identifying the marine units of different ages as well as the desiccated crusts. Based on the engincering properties measured. we consider the $1.6 \mathrm{~km}$ s seismic 
velocity to be too high for the location of the Holocene/ Pleistocene boundary unless the desiccated crust is well dereloped

A major advantage in continental shelf sediments is that the transgressive Holocene deposits can be identified with a high degree of certainty. Since they have never been subaterially exposed. they would possess all the characteristics of marine deposits with the calcareous fossils preserved intact. PreHolocene deposits may show the calcareous fossils only if they hatre not been completely destroyed by groundwater dissolution during the subsequent glacial period(s). Pedogenesis is therefore a key to the understanding on the Quaternary sequence stratigraphy of continental shelves. 16 January 1997

J. A. Fyfe, I. C. Selby, R. Shaw, J. W. C. James \& C. D. R. Evans reply: The authors thank Yin et al. for their discussion on the Quatemary of Hong Kong. Before dealing with the five points raised, the atuthors wish to emphasize that their paper is based on the detailed interpretation of over 5000 -line kilometres of high-resolution boomer seismic records. examination of the logs of thousands of offshore ground investigation boreholes and the detailed logging of several continuously sampled boreholes. Consequently. Hong Kong hals probably the most intensively investigated offshore area anywhere in the world. and the geometry, lithology and the origin of the oflshore formations are extremely well constrained.

Although Yim et al. ratise five points of concern. they do not present a similarly rigorous alternative model. However, relerence to their cited publications demonstrates that their interpretation of the offshore stratigraphy of Hong Kong is based entircly on the description. dating and analysis of sediments from a few borehole cores. with no reference to seismic records for lateral and regional correlation.

Dealing with their specific concerns in turn. the possibility of sample contamination leading to aberrations such as the so-called young-age bias in pre-Holocene sediments is not disputed by the authors. Indeed. we believe that it is an almost inevitable result of the eirculation of $\mathrm{CO}_{2}$-rich groundwater during lowstands. We share the scepticism about the reliability of arailable luminescence dates: in the sediment-laden conditions of the Pearl River estuary and the muddy shelf zone it is doubtful that the luminescence signals in the grains are fully zeroed in the turbid waters. Thus. in the absence of definitive dates we would not dismiss an Oxygen-isotope Stage 8 date for the Chek Lap Kok Formation. Yim ot al. have clearly misunderstood our conclusions when they suggest that we have clamed the sequence to be no older than Oxygen-isotope Stage 6. Lack of reliable dates would preclude our making such a far-reaching assumption

Secondly, the $60 \mathrm{~m}$ of Hang Hau Formation sediments described in southeastern waters laracly comprise channel infill of the Tung Lung Member. These channcls. which achieve their maximum development in this area, have been identified on seimic records. mapped out drilled and sampled. They are considered to be relic features of late-Weichselian atge. The large volumes of sediment certainly pose a problem. but wo believe that they were probably deposited by an abandoned branch of the proto Pearl River. Their preservation has resulted from the diversion of any potentially erosive fluvial influence and by the fact that the relatively deep waters and conscquent absence of strong sea-bed currents in this area have protected them from marine erosion during the Holocene.
Thirdly, we have referred to the sequence proposed by Yim (1994). It is considered to be worth restating here that this sequence comprises five marine-terrestrial cycles that have been inferred from the characteristics of borehole sediments with no relerence to regional surfaces that are clearly displayed on seismic records. For example. Yim proposes a tripartite subdivision in borehole samples from the West Lamma Channel. Seismic records from this area reveal a uniform seismic unit that displays homogeneous. faint reflections characteristic of uniform muddy sequences throughout Hong Kong. Further, the Yim (1994) approach appears to be based on the simplistic assumption that sandy sediments are terrestrial and muddy sediments are matrine. However. one of the defining characteristics of the Chek Lap Kok Formation is the lack of lateral continuity in the sediments. a fact that is clearly demonstrated on seismic profiles and supported by the logging of closely spaced boreholes. The authors accept that some of the finer-grained sediments may be estuarine or marine. but confidently assert that there is no evidence. on seismic records or in continuously sampled boreholes. for the five marine-terrestrial cycles proposed by Yim (1994).

Fourthly, the Holocene sediments that occur to the south of Hong Kong are an integral part of the Pearl River prodelta depositional system. Seismic records clearly show that they thin markedly southwards and are indeed absent on the outer shelf. where a variable lag of sand and gravel oceurs. Southward thinning of the offshore superficial sediments is an accepted component of the shell stratigraphy, but was not an issue directly addressed by the paper.

Fifthly. the authors unequivocally agree that the seismic velocity of the soft muddy sediments of the upper members of the Hang Hau Formation is probably nearer $1500 \mathrm{~m} \mathrm{~s}$ '. a velocity that is adopted when detailed studies of the mud sequences require accurate determinations of datum levels. However, experience confirms that a seismic velocity of $1600 \mathrm{~ms}^{-1}$ is a reliable value for the complete Quaternary sequence in Hong Kong. This velocity value compensates for the higher velocities encountered in the underlying Chek Lap Kok Formation. In any case. any error compounded by using a velocity of $1600 \mathrm{~m} \mathrm{~s}^{-1}$ would be at most $0.65 \mathrm{~m}$ in a $10 \mathrm{~m}$ sequence. Ironically. this would result in a thicker Hang Hat Formation than we have mapped. The base of the Holocene is. in all but a few areas. clearly identifiable on seismic records as a regional surface. This unconformity is the most reliably constrained surface in the model, having been drilled. sampled. dated and confidently confirmed at innumerable locations.

Yim at al. suggest that our representative seismic profiles are misleading and that the $\mathrm{R} 2$ reflector [sic] does not show the base of the Holocene deposits. The $R 2$ reflection is a very distinctive feature and may be traced throughout Hong Kong waters with a high degree of confidence. Clearly it is a diachronous surface. representing a northward transgression that occurred over a maximum of about 1000 years. As has been previously explained. the sequence of five marineterrestrial units proposed by Yim (1994) from features in the sedimentary record cannot be substantiated in the seismic record as they do not, in general. correspond with clear bounding surfaces.

We accept the evidence of both uranium-series dates given by Yim et al. (1990) and quoted the older, albeit more inexact. date merely as an illustration of the possible age of part of the Chck Lap Kok Formation. As with the radiocarbon and luminescence dates discussed earlier. there is simply insufficient dating evidence to establish a reliable chronology for the older 
sediments. Therelore. we maintain the alssertion made in our paper that the age of the formation must be considered at uncertain.

Lastly. We do not dispute the existence of a desiccated crust. though prefer to refer to such features as weathered horizons or paliacosols. Logging of continuously sampled boreholes has convincingly demonstrated that the Holocene/Pleistocene boundary is rarely characterized by a palacosol. as the base of the Holocene is a marine planation surface. Consequently any pre-existing palateosol would have been removed. Yim ot al. follow a circular argument in attempting to make the correlation. Indeed. We have recorded at the top of the Sham Wall Formation a $4 \mathrm{~m}$ thick weathered horizon and. although this is one of the arguments for this formation being of Eemian age. even a horizon of stech magnitude could be formed in a matter of hundreds of years of subaterial exposure in the tropical climate of Hong Kong. Palacosols develop on flood plains and interfluves. so are common intraformational features within the fluvial Chek Lap Kok Formation. Remote tests such as the CPTs cited by Yim a $t$ al. if indeed they are able to distinguish palateosols from other indurated horizons, which the authors doubt. Hould not distinguish between interformational and intraformational pedogenic horizons. Thus a model based on the random preservation of these features cannot be sustained. Further. weathered horizons cannot be identified on seismic sections. and despite the assertion by Yim et al that pedogenesis mal be the key to understanding of Quaternary sequence stratigraphy on continental shelves, the authors firmly believe that seismic interpretation provides the most reliable technique for lateral correlation between borcholes and the establishment of a regional stratigraphical model.

1 June 1998

\section{References}

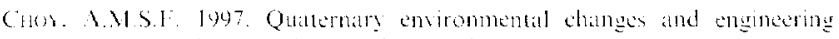
propertise of inner thell sediments from Hong Kong. In: thother.

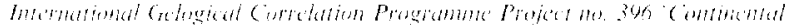

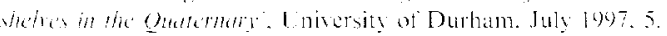

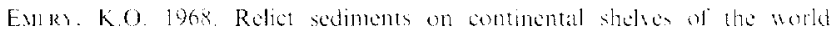

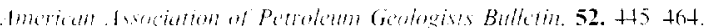

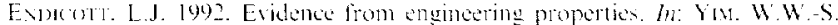

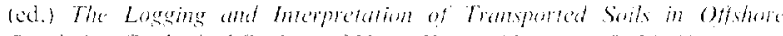
Buflower. Geological Society of llong Kong. Abstracts. 8. 39 48

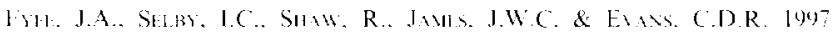
Quatemary sea-lesel change on the continental whell of Hons Kong

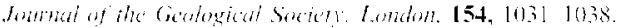

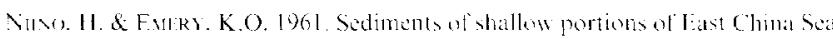

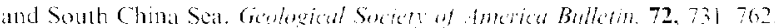

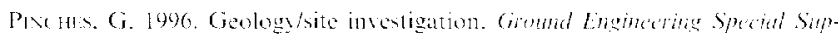

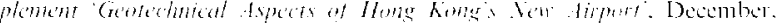
2224.

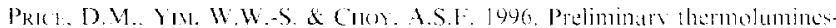
cence ages of inner shell edments from the new llong Kong Sirport sile

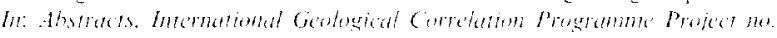

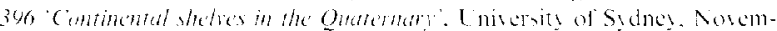
ber 1996.78 .

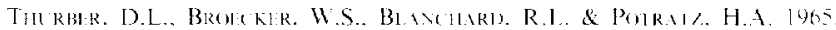

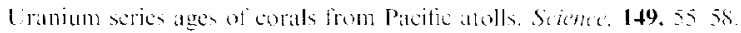

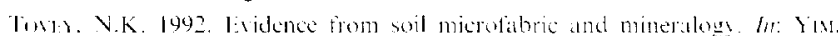

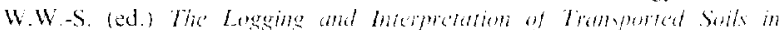

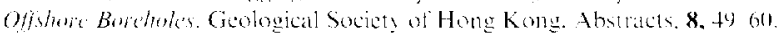

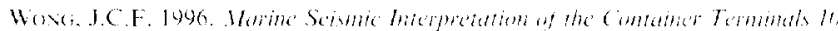
and l/ Situ. BSc Thesis. Department of Farth Scicnces, The Enicrsily of Hong Kong. Hong Kong.

Sin. W.W.-S. 1994. Offshore Quaternary sedinnents and their enginesing

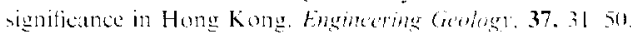

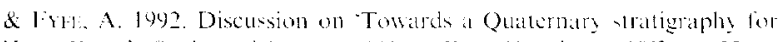

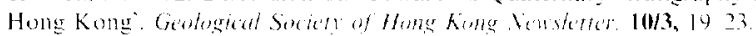

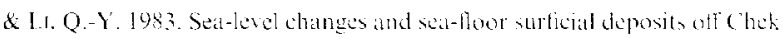

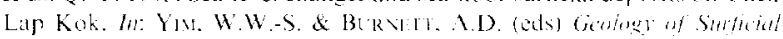

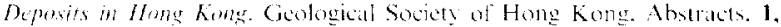
4859.

\& lowk. V.K. 1995. Desicuation of inner continentill sheff sediments during Quaternary bu seatevel stands. Gowtemint. 5/4. 34 35

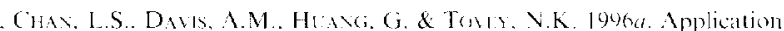
of magnetic susceptibility for mapping the flolocene/pre-Holocene bound-

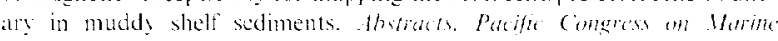

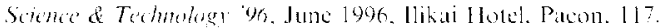

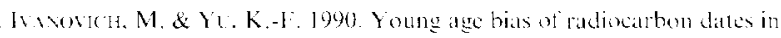
pre-tolocene marine deposits of Hong Kong and implications for

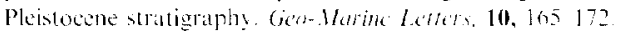

Ho Ave. G. \& LI. Q.-Y 1996 . Hudrologicat information on Hone Kom Waters obtained from the study of llolocene sediments. In: (imstal Infre-

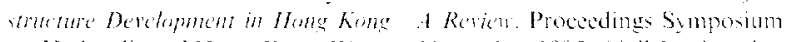
on Hudratulics of Hong Kong Waters. Nowember 1995. (ivil Engineering Department. Hong Kong Government. 97113.

J. A. Fyll. British Geologieal Survey. Murchison House, West Mains Road. Edinburgh EH9 3L $\mathrm{L}$. UK

R. SHAw. Hong Kong Geological Survey, Geotechnieal Fngineering Ottice. Cixil Engineering Building. 101 Princess Margaret Roald. Kowloon. Hong Kong. China.

1. C. StLbY. Coastal Geosciences, 27 Battery Road. Great Yarmouth. Norfolk NR30 3N. UK

J. W. C. Jamis \& C. D. R. Evans. British Geological Survey. Kingsley Dunham Center. Keyworth. Vottingham NG12 5GG. LK. 